\title{
Effect of electromyostimulation on intramyocellular lipids of the vastus lateralis in older adults: a randomized controlled trial
}

Maya Hioki ${ }^{{ }^{*}}$ D, Nana Kanehira ${ }^{2}$, Teruhiko Koike ${ }^{3}$, Akira Saito $^{4}$, Hideyuki Takahashi $^{5}$, Kiyoshi Shimaoka $^{6}$, Hisataka Sakakibara ${ }^{7}$, Yoshiharu Oshida ${ }^{3}$ and Hiroshi Akima $^{3}$

\begin{abstract}
Background: Excessive intramyocellular lipid (IMCL) accumulation is a primary cause of skeletal muscle insulin resistance, especially in older adults, and interventions that reduce $I M C L$ contents are important to improve insulin sensitivity. Electromyostimulation (EMS)-induced changes in IMCL content in older adults remain unknown. The purpose of this study was to clarify the effects of a single bout of EMS on the IMCL content of the vastus lateralis muscle in older adults.

Methods: Twenty-two physically active, non-obese older men and women were randomly assigned to an EMS intervention group ( $69.0 \pm 5.2$ years, $n=12)$ or a control group (68.4 \pm 3.5 years, $n=10)$. EMS was applied to the vastus lateralis (7 s on and $7 \mathrm{~s}$ off) for $30 \mathrm{~min}$; control participants sat quietly for $30 \mathrm{~min}$. IMCL content within the vastus lateralis was quantified with ${ }^{1} \mathrm{H}$-magnetic resonance spectroscopy $(n=7$ per group). Fasting plasma glucose and insulin values were determined from blood samples collected before and after the EMS intervention.
\end{abstract}

Results: EMS induced a significant reduction in plasma glucose ( $93.1 \pm 9.6$ to $89.5 \pm 9.1 \mathrm{mg} / \mathrm{dL}, p<0.01$ ), but not IMCL content $(15.7 \pm 15.7$ to $15.8 \pm 13.1 \mathrm{mmol} / \mathrm{kg}$ wet weight, $p=0.49)$ or insulin $(5.4 \pm 2.4$ to $4.7 \pm 2.7 \mu \mathrm{lU} / \mathrm{mL}, p=0.18)$. In the control group, no changes in IMCL content in the vastus lateralis was observed after prolonged quiet sitting.

Conclusion: EMS intervention for 30 min induces changes in plasma glucose, but no changes in IMCL content in older adults.

Trial registration: University hospital Medical Information Network (UMIN) Center ID: UMIN000020126. Retrospectively registered on December 222,015. https://upload.umin.ac.jp/cgi-open-bin/ctr_e/ctr_view.cgi?recptno=R000023242

Keywords: Energy substrate metabolism, ${ }^{1} \mathrm{H}$-magnetic resonance spectroscopy, Skeletal muscle, Blood biochemistry, Aging

\footnotetext{
* Correspondence: maya@mri.biglobe.ne.jp

'Graduate School of Medicine, Nagoya University, 65 Tsurumai, Showa-ku,

Nagoya, Aichi 466-8550, Japan

Full list of author information is available at the end of the article
}

\section{$\triangle B M C$}

C The Author(s). 2021 Open Access This article is licensed under a Creative Commons Attribution 4.0 International License, which permits use, sharing, adaptation, distribution and reproduction in any medium or format, as long as you give appropriate credit to the original author(s) and the source, provide a link to the Creative Commons licence, and indicate if changes were made. The images or other third party material in this article are included in the article's Creative Commons licence, unless indicated otherwise in a credit line to the material. If material is not included in the article's Creative Commons licence and your intended use is not permitted by statutory regulation or exceeds the permitted use, you will need to obtain permission directly from the copyright holder. To view a copy of this licence, visit http://creativecommons.org/licenses/by/4.0/. The Creative Commons Public Domain Dedication waiver (http://creativecommons.org/publicdomain/zero/1.0/) applies to the data made available in this article, unless otherwise stated in a credit line to the data. 


\section{Background}

Intramyocellular lipids (IMCLs) are an important energy substrate for adenosine triphosphate (ATP) production in skeletal muscle, especially during lower intensity physical activity [1]. However, IMCL contents are present at higher levels in older adults compared to younger adults [2-4]. Excessive IMCL accumulation is a primary cause of skeletal muscle insulin resistance [5]. IMCL contents are partly metabolized to ceramide, diacylglycerol, and Protein kinase $\mathrm{C}$ nuclear factor kappa B (PKC NF-kB), all of which can inhibit the insulin receptor signaling pathway in skeletal muscle [6]. Indeed, studies have demonstrated that IMCL contents are correlated with insulin sensitivity in humans, and increased IMCL contents in insulin-resistant participants are observed [7-9]. Thus, interventions that reduce IMCL contents are important in older adults to improve insulin sensitivity.

IMCL contents can be influenced by diet [10], physical exercise [11], and physical activity [12] in young adults, suggesting that IMCL turnover in response to exercise or diet indicates dynamic flexibility. However, compared with younger adults, IMCL contents in older adults are approximately 2 -fold higher at rest (before resistance exercise) and remain unchanged during the recovery period, indicating less flexibility in IMCL turnover [13]. According to a previous study [14], IMCL oxidation is reduced in older compared with younger adults during aerobic exercise at the same intensities and times. Furthermore, muscle volume, function, and metabolism decrease with aging [15]. Age-related muscle atrophy is markedly apparent in the quadriceps femoris (QF), which influences daily physical activities. Intramuscular adipose tissue accumulation is also preferentially observed along with QF muscle atrophy with aging [16]. Therefore, exercise may be necessary to reduce the IMCL content in the QF in older adults.

Electromyostimulation (EMS) of skeletal muscles induces involuntarily muscle contraction and enhances energy substrate utilization [17]. According to a study using positron emission tomography (PET) and H215O [18], single-bout EMS intervention over the vastus lateralis (VL) muscle for $12 \mathrm{~min}$ induces a change in the blood flow of muscle tissue. EMSinduced muscle activation may thus induce acute changes in IMCL metabolism. Thus, EMS is commonly used in clinical settings as rehabilitation after spinal cord injury, stroke, or physical inactivity to improve skeletal muscle morphology, muscle function, and metabolism. Levels of oxidative enzymes are increased following EMS training for a period [19]. According to recently pilot study, IMCL content in combined type I and type II fibers decreased slightly after EMS rehabilitation in the patient with rheumatoid arthritis (BMI, mean \pm SD $32.4 \pm 7.1 \mathrm{~kg}$ / $\mathrm{m}^{2}$ ). Molecular adaptations of skeletal muscle to bout EMS loading also occur in a very short time $[20,21]$. The change in IMCL content after acute exercise has been measured using biopsy and ${ }^{1} \mathrm{H}$-magnetic resonance spectroscopy ( ${ }^{1} \mathrm{H}$-MRS).

The purpose of this study was to clarify the effects in older adults of a single bout of 30-min EMS of the $\mathrm{VL}$ muscle on the IMCL content of the VL using non-invasive ${ }^{1} \mathrm{H}$-MRS. We hypothesized that EMS induces a decrease in the IMCL content of the VL in older adults.

\section{Methods}

\section{Participants}

Participant recruitment was conducted from January to July 2013, and all experiments were performed from July 2013 to February 2014. Twenty-two physically active, non-obese, independently living older men and women were enrolled in this study and were randomly assigned to an EMS group $(n=12)$ or a control group (without EMS) $(n=10)$. Exclusion criteria were based on the following requirements: 1) heart disease (e.g., myocardial infarction, angina pectoris, cardiac insufficiency), 2) cerebrovascular disease (e.g., cerebral infarction, hemorrhage), 3) extreme hypertension (e.g., systolic blood pressure (BP) $\geq 180 \mathrm{mmHg}$, diastolic BP $\geq 110 \mathrm{mmHg}$ ), and 4) with magnetic device such cardiac pacemaker. The Participants responded the clinical histories by questionnaires. Of the three participants with type 2 diabetes, one was receiving mitiglinide calcium hydrate (EMS group), one glibenclamide and mitiglinide calcium hydrate/voglibose, and one metformin (control group). All participants informed about the nature, purpose, and risks of the experimental procedures before their written informed consent was obtained. This study was approved by the Ethics Committee of the Graduate School of Medicine, Nagoya University. This is conforming to the standards set by the Declaration of Helsinki. The study adheres to CONSORT guidelines.

\section{Experimental protocol}

Flowchart of the experimental procedures and participants is shown in Fig. 1. The experimental protocol for the EMS (top) and control (bottom) groups is shown in Fig. 2. Before beginning the study, all participants were familiarized with the EMS at the laboratory once a week $\times 3$ times. The experimental protocol composed of measuring body composition and maximal voluntary contraction (MVC) during isometric knee extension, collecting blood samples, and performing assessment with ${ }^{1} \mathrm{H}$-MRS in the morning. For the ${ }^{1} \mathrm{H}$-MRS experiment, all participants arrived 


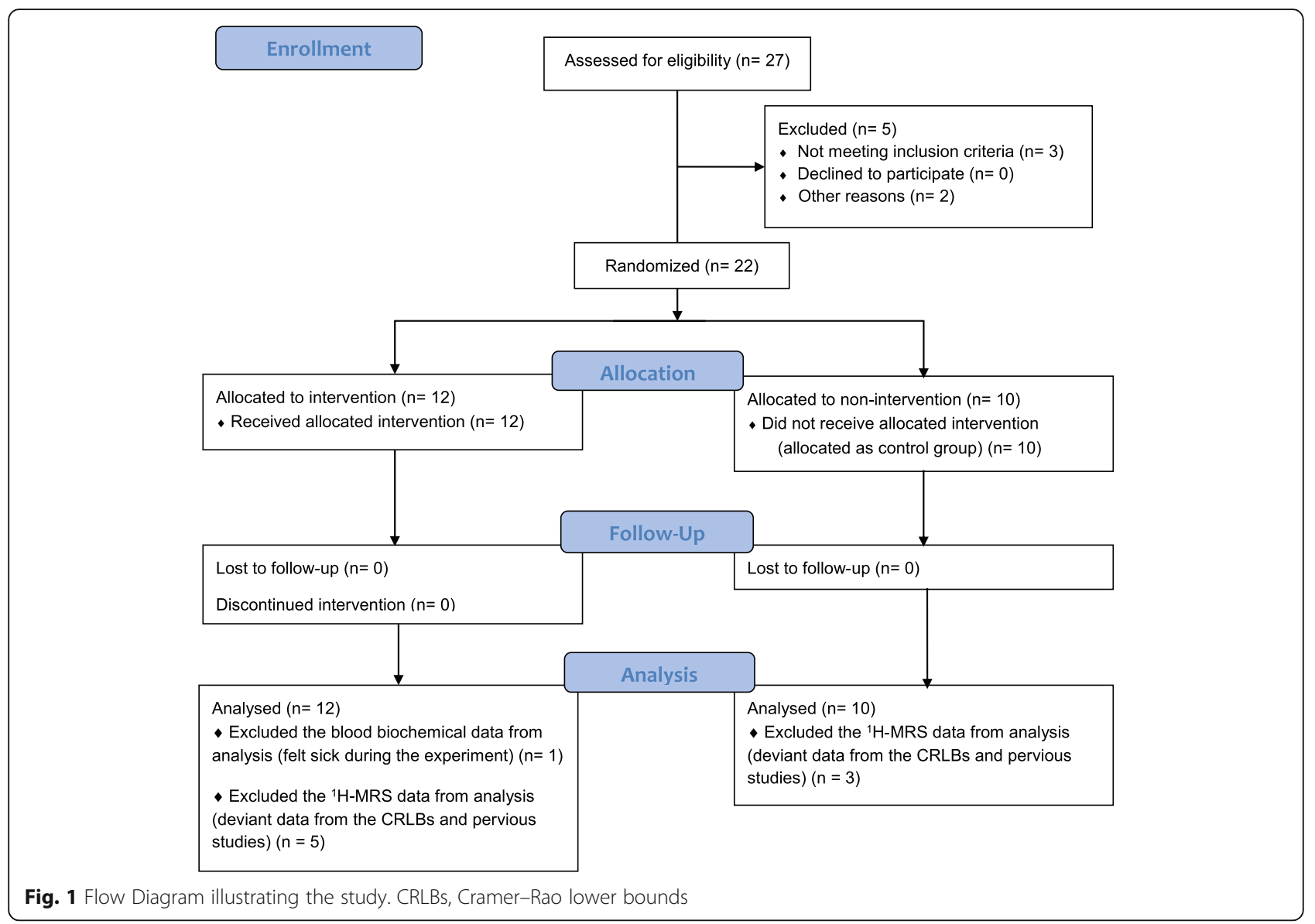

at the laboratory at 8:00 am after fasting $\geq 10 \mathrm{~h}$. Fasting blood samples were collected before and immediately after EMS. We applied EMS to the VL of the right leg for $30 \mathrm{~min}$. Whereas in the control group, blood was collected only before resting for $30 \mathrm{~min}$, because, we predicted that change in biochemistry levels would not induce during resting for $30 \mathrm{~min}$. The IMCL content in the VL was quantified by ${ }^{1} \mathrm{H}$-MRS before and immediately after the EMS in the EMS group, as well as before and after resting in the control group. Calculation of IMCL and extramyocellular lipid (EMCL) contents was performed with LCModel software (Stephen Provencher, Inc., Oakville, Ontario, Canada).

\section{EMS}

Transcutaneous EMS (Trio 300, Ito Co., Ltd.) was performed on the VL. Voltage was delivered via two $5 \times 9$ cm electrodes (Axelgaard Mfg. Co., Ltd.) applied to the skin. One was placed approximately $5 \mathrm{~cm}$ distal to the greater trochanter over the VL, and the other was placed approximately $5 \mathrm{~cm}$ proximal to the superior aspect of the knee joint of the VL. EMS intensity was set until the individual's maximum level of toleration. During EMS for $30 \mathrm{~min}$, output muscle contraction was monitored with a custom-made dynamometer (Takei Scientific Instruments Co. Ltd., Tokyo, Japan), and the maximal value of EMS-induced muscle force was recorded. Stimulation was performed at a frequency of $30 \mathrm{~Hz}$, pulse duration of $300 \mu \mathrm{s}$ biphasic rectangular, and contraction/relaxation durations of $7 \mathrm{~s}$ on and $7 \mathrm{~s}$ off for 30 $\min$.

Systolic BP, diastolic BP, and heart rate were measured before and after EMS for $30 \mathrm{~min}$ in the EMS group. Participants evaluated their pain with the visual analog scale on the day of the ${ }^{1} \mathrm{H}$-MRS experiment and 3 days after the experiment. The scale ranges from 0 to $100 \mathrm{~mm}$ with the zero-value indicating "no pain" and the 100-value indicating the "worst pain".

\section{Blood collection and analysis}

Blood tests were performed to determine the fasting levels of free fatty acid (FFA), triglyceride (TG), glucose, insulin, and hemoglobin A1c.

One participant felt sick during the experiment; this participant rested, consumed some sugar, and returned to the experiment. Therefore, we excluded the blood biochemical data after EMS for this one participant from 


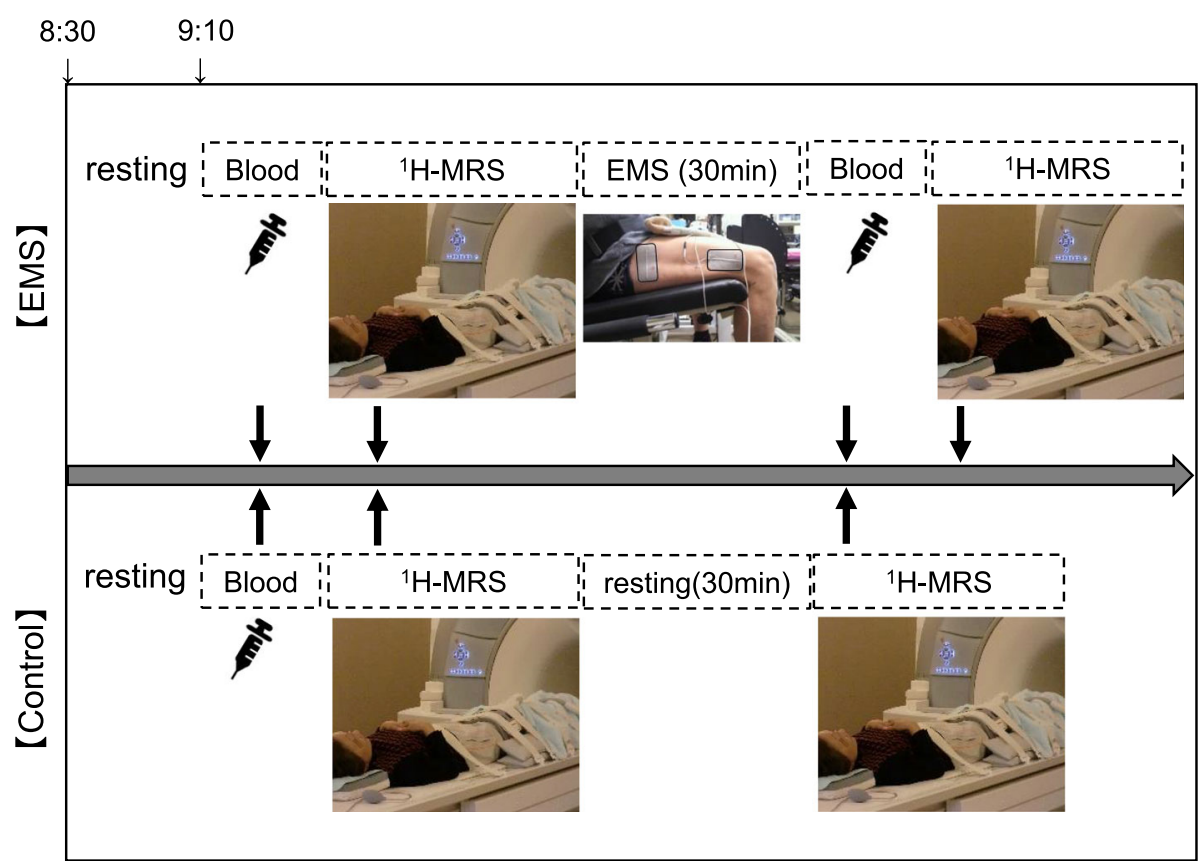

Fig. 2 Experimental protocol of EMS (top) and control (bottom) groups. All participants arrived at the laboratory at 8:00 am after $\geq 10 \mathrm{~h}$ of fasting. We applied EMS to the VL of the right thigh for $30 \mathrm{~min}$. IMCL and EMCL contents in the VL were quantified with ${ }^{1} \mathrm{H}$-MRS before and immediately after EMS in the EMS group, as well as before and after resting in the control group. Fasting blood samples were also collected before and immediately after EMS in the EMS group, as well as before resting in the control group. EMCL, extramyocellular lipid; EMS, electromyostimulation; ${ }^{1} \mathrm{H}-\mathrm{MRS}$, magnetic resonance spectroscopy; IMCL, intramyocellular lipid; VL, vastus lateralis

analysis. Moreover, IMCL and EMCL data of this participant were not included.

${ }^{1} \mathrm{H}-\mathrm{MRS}$

Before and immediately after EMS in the EMS group as well as before and after resting in the control group, ${ }^{1} \mathrm{H}$ MRS data were acquired on a 3.0-T MAGNETOM Verio (Siemens Healthcare GmbH, Eschborn, Germany) with a four-channel flex coil $(366 \times 174 \mathrm{~mm})$ wrapped around the thigh. The voxel size was $11 \times 11 \times 20 \mathrm{~mm}$. Visible adipose tissue, connective tissue, and vessels avoided, voxels were placed in the VL at the middle thigh between the greater trochanter and lateral condyle of the femur. In every participant, voxels were carefully placed at the same position while looking at the cross-sectional MR imaging at the mid-thigh level before and after EMS or resting in both groups. EMCLs are concentrated in distinct structures such as subcutaneous fat and fibrotic structures along muscle fibers in adipocytes (fasciae, septae). Depending on the exact position of the voxel, the EMCL signal can change by orders of magnitude [22].

Single voxel ${ }^{1} \mathrm{H}$-MRS measurements were performed using a point-resolved spatially localized spectroscopy (PRESS) sequence with the following acquisition parameters: TR/TE, 4000/30 ms, 128 averages. We were also used the unsuppressed water signal measured in the same voxel under the same shimming conditions as a reference signal [22].

\section{Post-processing}

Fitting of all ${ }^{1} \mathrm{H}$-MRS data was performed using LCModel version 6.2-4A (Stephen Provencher, Inc.) [23]. From the scanners to a Linux workstation, data were transferred. Metabolite quantification was performed using water scaling and eddy current correction. The water concentration was postulated to be $42.4 \mathrm{mmol}$ per $\mathrm{kg}$ wet weight based on the mean water content of $77 \%$ in muscle tissue [24]. The concentrations of IMCL- $\mathrm{CH}_{2}(1.3 \mathrm{ppm})$ and EMCL$\mathrm{CH}_{2}$ (1.5 ppm) were computed as mmol per liter of muscle tissue $(\mathrm{mM})$. IMCLs and EMCLs were collected for the $\mathrm{T} 1$ and $\mathrm{T} 2$ relaxation effects of the water reference using LCModel's control parameter, atth2o, and determined using the following equation: ext. (-TE/T2) [1 ext. $(-\mathrm{TR} / \mathrm{T} 1)$ ] [25], assuming relaxation times $\mathrm{T} 1=368$ $\mathrm{ms}, \mathrm{T} 2=89.4 \mathrm{~ms}$ and $\mathrm{T} 1=369 \mathrm{~ms}, \mathrm{~T} 2=77.6 \mathrm{~ms}$ for the IMCL-CH $\mathrm{CH}_{2}$ and EMCL-CH $\mathrm{CH}_{2}$, respectively [26]. The concentration of total lipid content was calculated by summing IMCL-CH2 and EMCL-CH2 concentrations and dividing by 31 . The value 31 was accorded to the assumption $[22,27]$ that the average number of methylene protons is 62 per triglyceride molecule (equivalent to $31 \mathrm{CH} 2$ groups) [28]. To convert $\mathrm{mM}$ to $\mathrm{mmol}$ per $\mathrm{kg}$ wet weight, 
the value was divided by the tissue density $(1.05 \mathrm{~kg} / \mathrm{L}$ for normal muscle tissue).

${ }^{1} \mathrm{H}$-MRS spectra in participants in the EMS group $(n=12)$ and control group $(n=10)$ were acquired. All ${ }^{1}$ H-MRS data $(n=22)$ were processed using LCModel version 6.2-4A (Stephen Provencher, Inc., LCModel and LCMgui user's manual) [23]. Before looking at the IMCL concentrations, the estimated standard deviations (SDs) (Cramer-Rao lower bounds [CRLBs]) expressed in percent of the estimated concentrations were checked. \%SD $<20 \%$ has often been used as a very rough criterion to estimate acceptable reliability. Moreover, as error estimates of upper bounds, we compared our data with the data of previous studies (range of IMCL data, younger adults $2.4-26.3 \mathrm{mmol} / \mathrm{kg}$ wet weight; older adults $6.7-$ $14.9 \mathrm{mmol} / \mathrm{kg}$ wet weight) $[12,29,30]$, and obviously deviant data were excluded. In the present study, IMCL data (including before and after EMS) in four of the 12 older adults in the EMS group and IMCL data (including before and after resting) in three of the 10 older adults in the control group showed $\% \mathrm{SD}>20 \%$ according to CRLBs. Moreover, IMCL data in one of the 12 older adults in the EMS group showed obviously deviant data. Therefore, we excluded the data of these older adults from analysis and acquired IMCL data from the VL for seven participants in the EMS group and seven in the control group.

\section{Muscle strength}

The participants were familiarized with the experiments at the laboratory at least 3 weeks before testing. MVC force during isometric knee extension were measured using a custom-made dynamometer (Takei Scientific Instruments Co. Ltd.). The dynamometer was strapped to the hip and thigh, and the knee joint was flexed at $90^{\circ}$ $\left(0^{\circ}=\right.$ fully extended $)$. We adjusted the length of the vertical lever arm for the leg length of the participants and fixed with straps during MVC tests. MVC tests of the right leg were performed three or four at about 3-min intervals. We recorded the maximal attempt of two tests of three or four tests that yielded the highest force. Isometric knee extension force is expressed as an absolute value $(\mathrm{Nm})$. During the EMS intervention, the EMSinduced isometric knee extension force was normalized to the muscle strength MVC.

\section{Physical activity levels}

The physical activity level was acquired from records of a three-dimensional ambulatory accelerometer (Lifecorder, Suzuken Co., Nagoya, Japan) for 10 days. Technical details were provided by Kumahara [31] and the manufacturer. The values ranging from 0.06 to $1.94 \mathrm{~g}$ ( $1.00 \mathrm{~g}$ is equal to the acceleration of free fall) were assessed $\mathrm{A}$ $32-\mathrm{Hz}$ sampling acceleration. The physical activity level was expressed as time and metabolic equivalent $\times$ hours (MET h). See our previous study [12] for additional details.

\section{Dietary parameters and analysis}

Dietary intake during the 3 days before ${ }^{1} \mathrm{H}$-MRS assessments and the habitual dietary intake of the participants were determined by a nutritionist. During the 3 days before $1 \mathrm{H}$-MRS assessments, the dietary intake was calculated from diaries and photos. Habitual dietary intake was estimated using a food frequency questionnaire, Ver. 2.0, which included 29 food and beverage items, and cooking methods of 10 series. The questionnaire asked about the average intake and frequency of consumption of each food. To describe consumption frequency, five categories were used as the follow; almost always, often, sometimes, rarely, or never. Dietary assessment showed the energy ( $\mathrm{kcal} /$ body weight), carbohydrate ( $\mathrm{g} /$ body weight), protein ( $\mathrm{g} /$ body weight), and fat (g/body weight) intake for the 3 days before ${ }^{1} \mathrm{H}$-MRS as well as dietary habits.

\section{Statistics analysis}

All data are shown as the means and SD. Analysis was performed by the investigators knowing which participants assigned to the EMS group. Differences between the EMS group and control group were analyzed using the Mann-Whitney test, and the differences between before and after EMS and resting for 30 min were analyzed using the Wilcoxon signed-rank test. The effect size (r) between the EMS and control groups was calculated by dividing $\mathrm{Z}$ by the square root of $\mathrm{N}(r=\mathrm{Z} / \sqrt{ } \mathrm{N})$, where $\mathrm{N}$ is the total number of participants, and the value of $\mathrm{Z}$ is calculated with the Wilcoxon signed-rank test. An effect size of 0.1 is considered small, 0.3 is moderate, and 0.5 is large. Analyses were performed with SPSS (version 24.0; SPSS Inc., Chicago, IL, USA). Statistical significance was set at $p<0.05$.

\section{Results}

\section{Characteristics of the study participants}

The characteristics of the study subjects are provided in Table 1. The data for physical characteristics, blood biochemistry, skeletal muscle profiles, physical activity levels ( $\mathrm{min}$ ), dietary intake during the 3 days before ${ }^{1} \mathrm{H}$ MRS, and dietary habit profiles did not significantly differ between the EMS and control groups. Only the physical activity level (MET h) was significantly different between groups. Effect sizes (r) between EMS and control groups were small to medium.

\section{EMS-induced force output}

EMS-induced muscle force $(\mathrm{N})$ was $37.1 \pm 30.5$ at the maximal value. This corresponded to $17.4 \pm 11.3 \%$ of 
Table 1 Characteristics of the study participants

\begin{tabular}{|c|c|c|c|}
\hline & EMS & Control & Effect size ( $r)$ \\
\hline No. of subjects (men/women) & $12(5 / 7)$ & $10(4 / 6)$ & \\
\hline \multicolumn{4}{|l|}{ Physical characteristics } \\
\hline Age (years) & $69.0 \pm 5.2$ & $68.4 \pm 3.5$ & -0.01 \\
\hline Height (cm) & $159.0 \pm 11.9$ & $157.1 \pm 6.9$ & -0.01 \\
\hline Weight (kg) & $55.7 \pm 10.6$ & $56.0 \pm 7.7$ & -0.06 \\
\hline $\mathrm{BMI}\left(\mathrm{kg} / \mathrm{m}^{2}\right)$ & $21.9 \pm 2.3$ & $22.7 \pm 2.3$ & -0.11 \\
\hline \multicolumn{4}{|l|}{ Blood biochemistry } \\
\hline Glucose (mg/dL) & $94.1 \pm 9.8$ & $97.7 \pm 25.4$ & -0.04 \\
\hline Insulin ( $\mu \mid \mathrm{U} / \mathrm{mL})$ & $5.5 \pm 2.4$ & $7.8 \pm 7.3$ & -0.11 \\
\hline $\mathrm{FFA}(\mu \mathrm{Eq} / \mathrm{L})$ & $714.0 \pm 161.9$ & $749.9 \pm 265.3$ & -0.15 \\
\hline $\mathrm{TG}(\mathrm{mg} / \mathrm{dL})$ & $105.2 \pm 77.4$ & $87.2 \pm 43.6$ & -0.08 \\
\hline HbA1c (\%) & $5.9 \pm 0.4$ & $6.0 \pm 0.5$ & -0.13 \\
\hline \multicolumn{4}{|l|}{ Skeletal muscle profiles } \\
\hline IMCL (mmol/kg wet weight) & $15.7 \pm 15.7$ & $13.6 \pm 15.8$ & -0.02 \\
\hline EMCL (mmol/kg wet weight) & $28.5 \pm 15.6$ & $27.5 \pm 14.2$ & -0.02 \\
\hline MVC during isometric knee extension (Nm) & $71.6 \pm 35.7$ & $65.5 \pm 25.0$ & -0.01 \\
\hline \multicolumn{4}{|l|}{ Physical activity } \\
\hline Physical activity level (min) & $93.8 \pm 17.0$ & $113.6 \pm 27.2$ & -0.39 \\
\hline Physical activity level (MET h) & $4.5 \pm 1.0^{*}$ & $5.7 \pm 1.7$ & -0.42 \\
\hline Number of steps & $8991.8 \pm 1722.7$ & $11,123.2 \pm 2990.0$ & -0.35 \\
\hline \multicolumn{4}{|l|}{ Dietary intake during the 3 days before ${ }^{1} \mathrm{H}-\mathrm{MRS}$} \\
\hline Energy (kcal/body weight) & $35.8 \pm 9.2$ & $36.6 \pm 7.3$ & -0.14 \\
\hline Carbohydrates (g/body weight) & $4.9 \pm 1.0$ & $4.8 \pm 0.9$ & -0.01 \\
\hline Protein (g/body weight) & $1.4 \pm 0.4$ & $1.5 \pm 0.4$ & -0.08 \\
\hline Fat (g/body weight) & $1.1 \pm 0.5$ & $1.2 \pm 0.3$ & -0.28 \\
\hline \multicolumn{4}{|l|}{ Dietary habits } \\
\hline Energy (kcal/body weight) & $36.8 \pm 7.5$ & $33.5 \pm 7.6$ & -0.15 \\
\hline Carbohydrates (g/body weight) & $5.0 \pm 1.0$ & $4.5 \pm 0.9$ & -0.17 \\
\hline Protein (g/body weight) & $1.4 \pm 0.4$ & $1.2 \pm 0.3$ & -0.30 \\
\hline Fat (g/body weight) & $1.2 \pm 0.3$ & $1.0 \pm 0.3$ & -0.22 \\
\hline
\end{tabular}

Values are means \pm SD. ${ }^{*} p<0.05$ versus control group. $B M I$ body mass index, $E M C L$ extramyocellular lipid, ES effect size, $F F A$ free fatty acid, $H b A 1 c$ hemoglobin A1c, ${ }^{1} H$-MRS magnetic resonance spectroscopy, IMCL intramyocellular lipid, MET $h$ metabolic equivalent $\times$ hours, MVC maximal voluntary contraction, TG triglyceride. Data for IMCL and EMCL: EMS group, men $n=5$, women $n=2$; control group, men, $n=4$, women $n=3$

MVC. Systolic BP, diastolic BP, and heart rate did not change significantly in the EMS group. Pain evaluation with the visual analog scale was in the range of $0-25$ $\mathrm{mm}(5.0 \pm 11.2 \mathrm{~mm})$ on the day of the ${ }^{1} \mathrm{H}$-MRS experiment and the 3-day period after the experiment. The mean visual analog scale score includes the data in the 5 out of 7 participants.

IMCL and EMCL contents in the EMS and control groups ${ }^{1} \mathrm{H}$-MRS spectra for the quantification of IMCLs obtained from the VL before and after EMS intervention or resting for $30 \mathrm{~min}$ for two 66-year-old men are shown in Fig. 3. Figure 4 shows the comparison of IMCL and EMCL contents between before and after the EMS intervention and resting for $30 \mathrm{~min}$. No changes after EMS were observed in IMCL $(15.7 \pm 15.7$ to $15.8 \pm 13.1 \mathrm{mmol} / \mathrm{kg}$ wet weight, $p=0.49)$ or EMCL $(28.5 \pm 15.6$ to $26.0 \pm 12.0$ $\mathrm{mmol} / \mathrm{kg}$ wet weight, $p=0.49)$ contents of the VL. In the control group, no changes in IMCL $(13.6 \pm 15.8$ to $13.7 \pm$ $5.7 \mathrm{mmol} / \mathrm{kg}$ wet weight, $p=0.49)$ or EMCL $(27.5 \pm 14.2$ to $30.9 \pm 9.3 \mathrm{mmol} / \mathrm{kg}$ wet weight, $p=0.49$ ) contents of the VL were observed after prolonged quiet sitting.

Effect of EMS on the blood biochemistry concentrations Effects of EMS on the blood biochemistry concentrations are shown in Fig. 5. The plasma glucose 


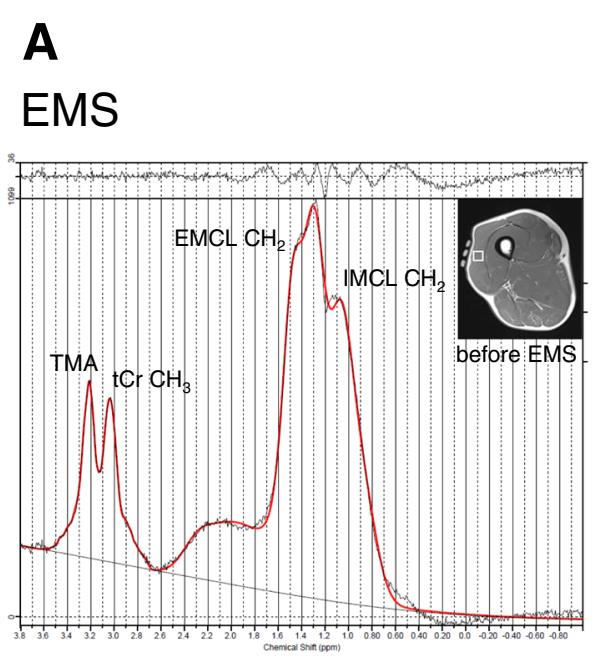

\section{C Control}

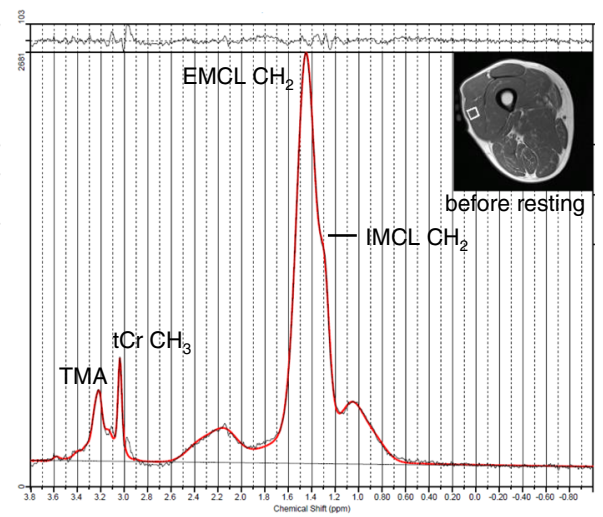

B

\section{D}
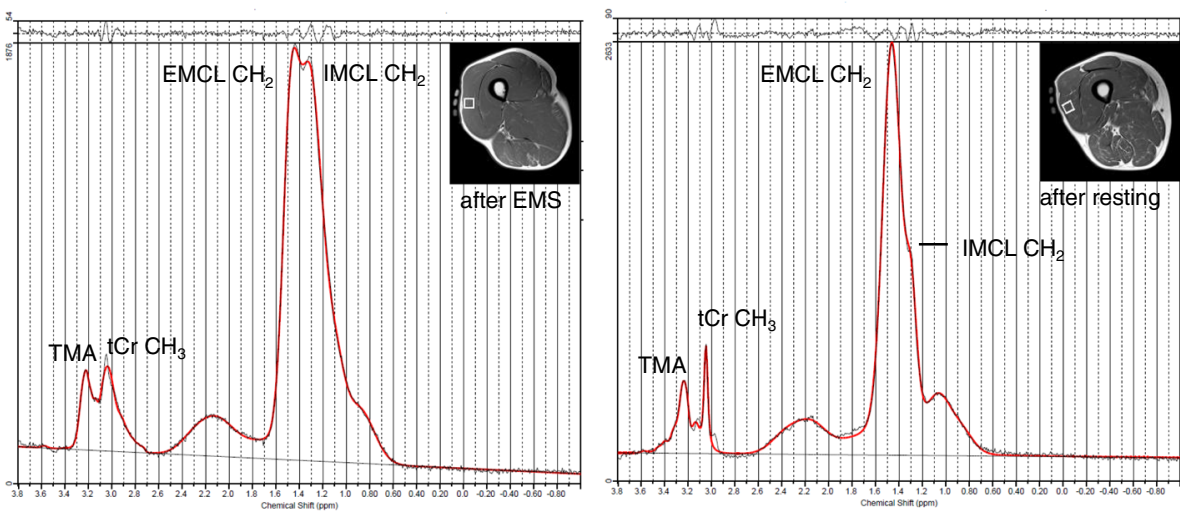

Fig. $3^{1} \mathrm{H}$-MR spectra of the VL before and after the EMS intervention or resting. $\mathbf{A}$ and $\mathbf{B}$ before and after the EMS intervention (66-year-old men); $\mathbf{C}$ and $\mathbf{D}$ before and after resting for 30 min (66-year-old men). Signals are indicated as IMCL-CH 2 at 1.3 ppm, EMCL-CH ${ }_{2}$ at 1.5 ppm, tCr-CH at $3.0 \mathrm{ppm}$, and TMA at $3.2 \mathrm{ppm}$. EMCL, extramyocellular lipid; IMCL, intramyocellular lipid; tCr, total creatine; TMA, trimethyl-ammonium

concentration decreased significantly from before to after the EMS intervention (93.1 \pm 9.6 to $89.5 \pm 9.1 \mathrm{mg} /$ $\mathrm{dL}, p<0.01)$, whereas insulin $(5.4 \pm 2.4$ to $4.7 \pm 2.7 \mu \mathrm{IU} /$ $\mathrm{mL}, p=0.18)$, FFA $(691.4 \pm 148.5$ to $681.1 \pm 187.8 \mu \mathrm{Ep} / \mathrm{L}$, $p=0.72)$, and TG $(107.8 \pm 80.6$ to $103.3 \pm 63.5 \mathrm{mg} / \mathrm{dL}$, $p=0.68)$ did not change significantly in the EMS group.

\section{Discussion}

The present study demonstrated that EMS intervention for $30 \mathrm{~min}$ induces changes in plasma glucose, but no change in IMCL content in the VL of older adults.

EMS directly stimulates the motor nerve, thus resulting in a random pattern of recruitment; in other words, EMS-induced motor unit recruitment is non-selective (a reversal of the size principle) [17]. Indeed, molecular adaptations of skeletal muscle to EMS loading are drastic $[20,21]$. Therefore, we speculated that EMS can induce a decrease in the IMCL content of the VL in older adults. However, our study results do not support this hypothesis. IMCL turnover in response to aerobic and resistance physical exercises is dynamic and flexible in young adults [32]. IMCLs are utilized as energy substrates by aerobic $[33,34]$ and resistance physical exercises $[35,36]$, and subsequently, FFAs are re-esterified in myocytes and recover. In contrast, IMCL turnover during physical exercise or physical activity in older adults seems to differ compared to that in younger adults. The contribution of IMCLs to whole-body fat oxidation during aerobic exercise is reduced with aging [14].

Our previous study also demonstrated that daily lightintensity physical activity is significantly and inversely correlated with IMCL content in younger adults, but not in older adults, suggesting that aging itself causes this effect [12]. Our results indicated that the IMCL content did not change after a 30-min EMS intervention in older adults. This result is agreement with a study showing 

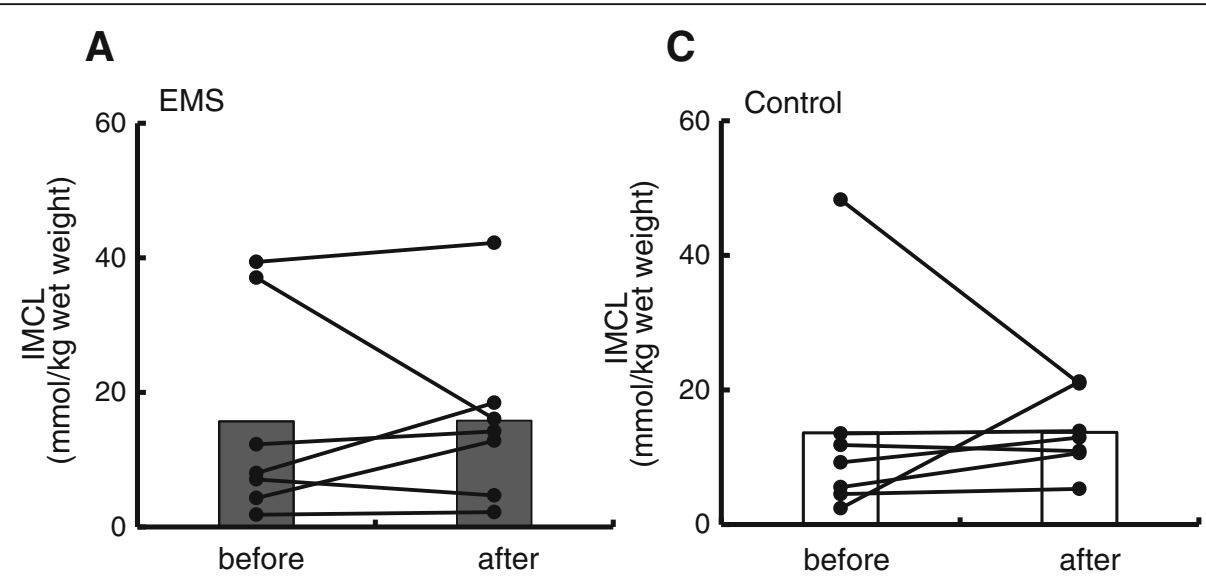

B

D
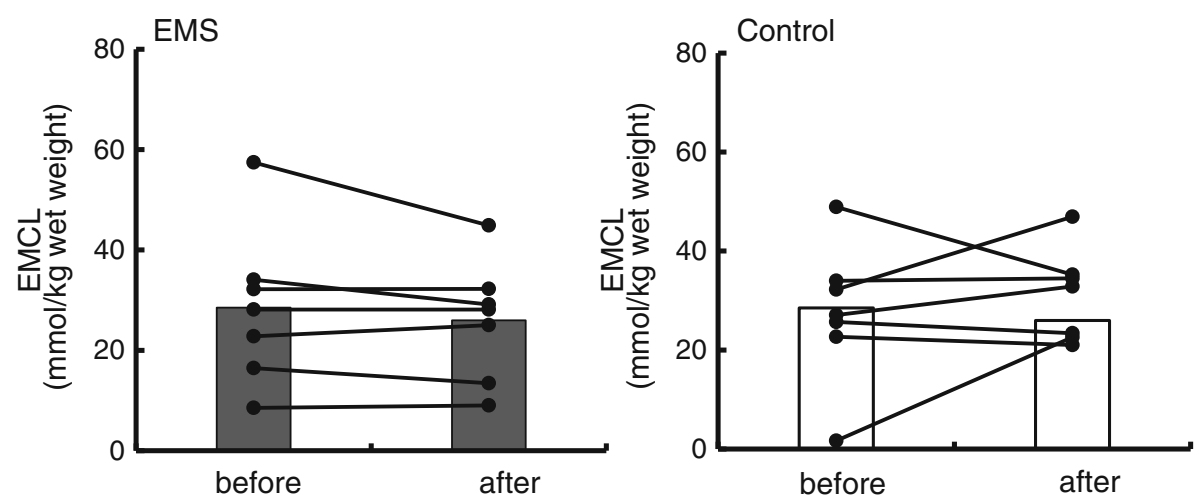

Fig. 4 Comparison of IMCL and EMCL contents between before and after the EMS intervention or resting. EMS intervention (men $n=5$; women $n=2, \mathbf{A}$ and $\mathbf{B}$ ) or resting for 30 min (men $n=4$; women $n=3, \mathbf{C}$ and D). EMCL, extramyocellular lipid; EMS, electromyostimulation; IMCL, intramyocellular lipid

that compared to younger adults, the IMCL content in older adults is approximately 2 -fold higher at rest (before resistance exercise) and remains unchanged during the recovery period [13].

Inflexibility of IMCL metabolism seems to be induced by both a decrease in IMCL turnover and an increase in delivery of FFAs to muscle, which may be a result of a decline in muscle metabolic function with aging. Therefore, our finding suggests that IMCL metabolism during EMS is inflexible in older adults.

Our findings are consistent with the result in young adults, in whom whole body glucose uptake during a euglycemic clamp is acutely increased in response to 20 min of EMS as well as after EMS. These changes are insulin independent and AMP-activated protein kinase dependent [37]. Acute AMP-activated protein kinase activation suppresses glycogen synthesis and increases glucose transport [38]. We observed that plasma glucose decreased significantly after $30 \mathrm{~min}$ of EMS; in contrast, the insulin concentration was stable. During voluntary physical exercise, changes in fat and carbohydrate metabolism rates depend on the exercise intensity and duration. With increasing exercise intensity, plasma FFA oxidation progressively shifts to blood glucose oxidation. In contrast, during physical exercise, plasma FFAs and glucose availability progressively increase over time [39]. In contrast, according to a study using EMS, PET, and $\mathrm{H} 215 \mathrm{O}$, the percentages of activated regions of interest (i.e., those showing increases in the blood flow area) in the thigh area were $50.6 \%$ at $5 \% \mathrm{MVC}$ and $62.2 \%$ at $10 \%$ MVC [18]. This indicates that EMS-induced knee extension force reflects an increase in involved muscle fibers. Therefore, we aimed to activate muscle contraction above 10\% MVC during EMS. Indeed, the EMS-induced knee extension force showed 17\% MVC. The VL volume accounts for approximately $30 \%$ of the QF muscles [40]. Our EMS intensity protocol may be high intensity for VL. Our results suggest that EMS can decrease plasma glucose in an insulin-independent manner.

EMS is an efficient to induce torque increases, however it is limited by the development of neuromuscular fatigue [41]. During maximal exercise, when a steadystate situation is never achieved, the ATP demand of muscle contraction is very high, and muscle fatigue 

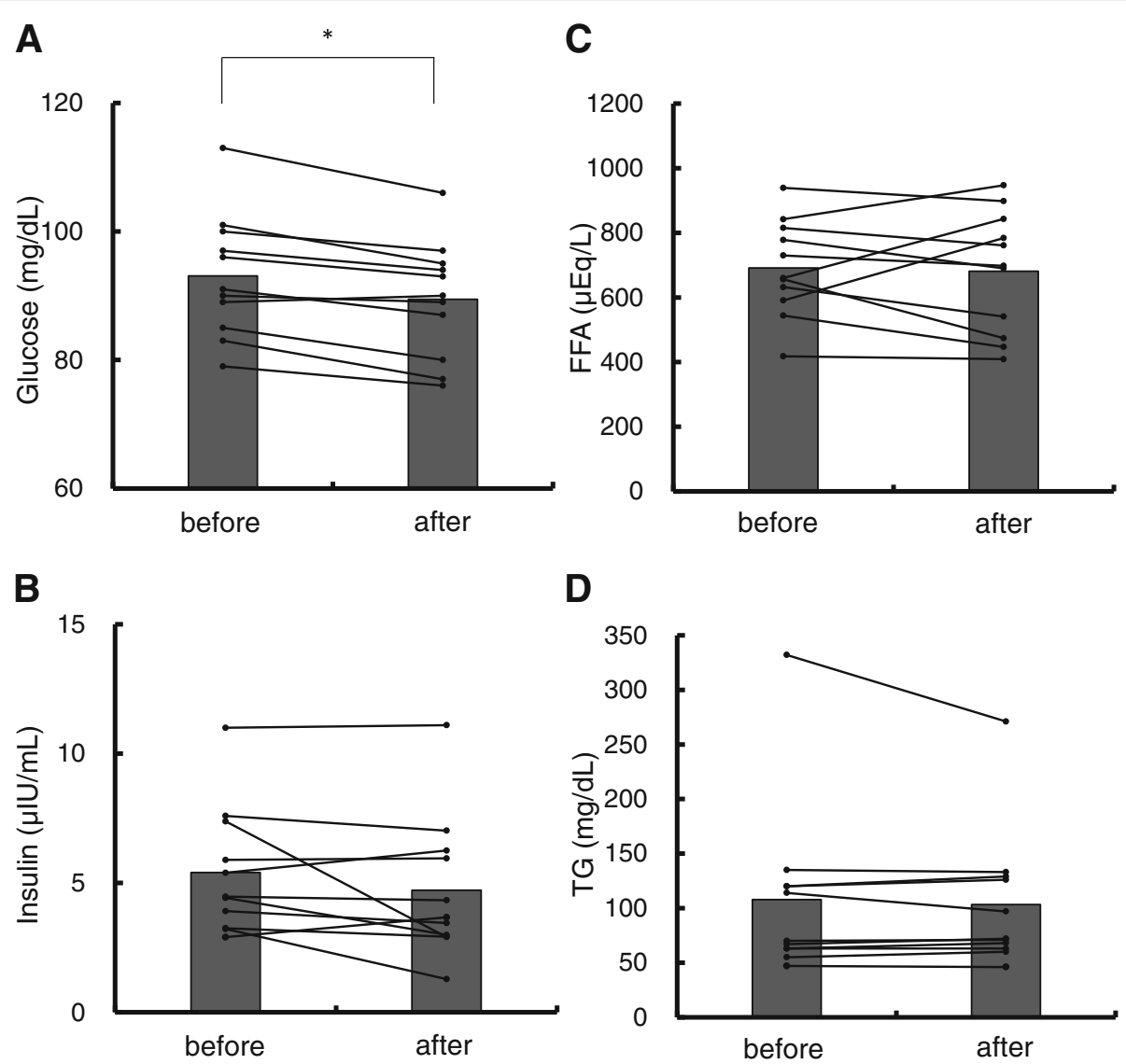

Fig. 5 Comparison of blood biochemistry between before and after the EMS intervention. A, glucose; $\mathbf{B}$, insulin; C, FFA; $\mathbf{D}, T$ TG. men = 5; women = 6. * $p<0.01$. EMS, electromyostimulation; FFA, free fatty acid; TG, triglyceride

occurs rapidly. Pulse frequency and duration of EMS give an impact on muscle torque production and fatigue [41, 42]. Although similar torque output during EMS, high-frequency EMS caused greater fatigue compared with low-frequency EMS [42]. Therefore, we selected the intermittent EMS (i.e., $7 \mathrm{~s}$ on-off cycle) at low-frequency stimulation (i.e., $30 \mathrm{~Hz}$ ) to minimize the neuromuscular fatigue, however muscle fatigue might occur in the older adult by EMS in the study.

Many previous studies have reported that EMS training or rehabilitation result change in muscle morphology, function, and metabolism, i.e., oxidative enzyme activity, muscle fiber type, muscle fiber size, muscle strength [19]. Recently several studies [43, 44] have reported that IMCL content decreased slightly in the patient with rheumatoid arthritis after EMS rehabilitation for a period 16 weeks, and fasting glucose level decreased in the patients with type 2 diabetes after EMS rehabilitation for a period 8 weeks. Although our study verified change in bout of EMS, EMS rehabilitation for period might result influence of IMCL content.

EMCLs (i.e., fat tissue) are concentrated in distinct structures such as subcutaneous fat and fibrotic structures along muscle fibers in adipocytes (fasciae, septae) [22]. EMCLs are relatively metabolically inert, and capable of supplying a large fraction of metabolic substrates, mainly during very low intensity exercise [39, 45]. We found that EMCL content was constant after EMS in older adults. Therefore, our results suggest that lipolysis within EMCL (adipocytes) was not stimulated during EMS.

Our study has several limitations. First, the sample size for IMCL content was small. We instituted an exclusion criterion of $\%$ SD $<20 \%$ CRLBs as an estimate of acceptable reliability. Moreover, as error estimates of upper bounds, our data were comparable with the data of previous studies [12, 29], and obviously deviant data were excluded. The IMCL data did not satisfy the exclusion criterion in eight of the 22 older adults in both groups. In contrast, the effect size between EMS and control groups was small to medium. Second, although blood biochemistry was measured before and after EMS, blood biochemistry was measured only before resting for $30 \mathrm{~min}$ in the control group. One participant felt sick during the experiment. Therefore, we excluded the blood biochemical data after EMS of this one participant from analysis. 


\section{Conclusions}

In conclusion, the EMS intervention induced a significant reduction in plasma glucose, but not IMCL content, in the VL of older adults. The findings suggested that a single bout of 30-min EMS intervention affects plasma glucose, whereas IMCL metabolism during EMS is inflexible in older adults. Further studies are needed to determine whether the IMCL content decreases following EMS in older adults. For example, it is an experiment to determine the suitable protocol, i.e., EMS intensity, period, frequency duration time.

\begin{abstract}
Abbreviations
ATP: Adenosine triphosphate; BP: Blood pressure; CRLBs: Cramer-Rao lower bounds; EMCL: Extramyocellular lipid; EMS: Electromyostimulation; FFA: Free fatty acid; ${ }^{1} \mathrm{H}-\mathrm{MRS}$ : Magnetic resonance spectroscopy; IMCL: Intramyocellular lipid; MET h: Metabolic equivalent $\times$ hours; MVC: Maximal voluntary contraction; PET: Positron emission tomography; QF: Quadriceps femoris; SD: Standard deviation; tCr: Total creatine; TG: Triglyceride; VL: Vastus lateralis
\end{abstract}

\section{Acknowledgments}

We are grateful to Haruo Isoda, MD, Atsushi Fukuyama, PhD, and Akira Ishizuka, RT, at Nagoya University Brain \& Mind Research Center; to Kiyoji Hotta, RN, at Nagoya University; to Yuko Shibata, PhD, at the Nagoya University Sports Club; and to Hitomi Sakakibara at Tokaigakuen University for helping with this project.

\section{Authors' contributions \\ Contributed to the concept and design of the study: all authors. Performed the experiments: MH, NK and AS. Performed participant's recruit: KS. Analyzed the data: $\mathrm{MH}$ and $\mathrm{HT}$. Wrote critical revisions of the manuscript: $\mathrm{MH}, \mathrm{AS}, \mathrm{TK}$, and HA. Read and approved the final version of the manuscript: all authors.}

\section{Funding}

This project was supported in part by a Grant-in-Aid for Challenging Exploratory Research from the Ministry of Education, Culture, Sports, Science and Technology (\#23650432) to HA and the Descente and Ishimoto Memorial Foundation for the Promotion of Sport Science to YO. The Ministry of Education, Culture, Sports, Science and Technology and Descente and Ishimoto Memorial Foundation have no role in study design; collection, management, analysis, and interpretation of data; writing of the manuscript; and the decision to submit the manuscript for publication.

\section{Availability of data and materials}

The datasets used and/or analyzed during the current study are available from the corresponding author on reasonable request.

\section{Declarations}

\section{Ethics approval and consent to participate}

All participants provided written informed consent to participate in this study, which was conducted according to the Declaration of Helsinki and approved by the Ethics Committee of the Graduate School of Medicine, Nagoya University.

\section{Consent for publication}

Not applicable.

\section{Competing interests}

The authors declare that they have no conflicts of interest.

\section{Author details}

'Graduate School of Medicine, Nagoya University, 65 Tsurumai, Showa-ku, Nagoya, Aichi 466-8550, Japan. ²Department of Health and Nutrition, Tokaigakuen University, 2-901 Nakahira, Tenpaku, Nagoya, Aichi 468-8514, Japan. ${ }^{3}$ Research Center of Health, Physical Fitness \& Sports, Nagoya University, 1 Furo, Chikusa-ku, Nagoya, Aichi 464-8601, Japan. ${ }^{4}$ Center for
Health and Sports Science, Kyushu Sangyo University, 2-3-1 Matsukadai, Higashi-ku, Fukuoka, Fukuoka 813-8503, Japan. ${ }^{5}$ Japan Institute of Sports Sciences, 3-15-1 Nishigaoka, Kita-ku, Tokyo 115-0056, Japan. ${ }^{6}$ Department of Human Wellness, Tokaigakuen University, 21-233 Nishinohora, Ukigai, Miyoshi, Aichi 470-0207, Japan. ${ }^{7}$ Ichinomiya Kenshin College of Nursing, 5-4-1 Jouganndoori, Ichinomiya, Aichi 491-0063, Japan.

Received: 14 February 2021 Accepted: 26 May 2021

Published online: 22 June 2021

\section{References}

1. Egan B, Zierath JR. Exercise metabolism and the molecular regulation of skeletal muscle adaptation. Cell Metab. 2013;17(2):162-84. https://doi.org/1 0.1016/j.cmet.2012.12.012.

2. Crane JD, Devries MD, Safdar A, Hamadeh MJ, Tarnopolsky MA. The effect of aging on human skeletal muscle mitochondrial and intramyocellular lipid ultrastructure. J Gerontol A Biol Sci Med Sci. 2010;65A(2):119-28. https://doi. org/10.1093/gerona/glp179.

3. Cree MG, Newcomer BR, Katsanos CS, Sheffield-Moore M, Chinkes D, Aarsland $A$, et al. Intramuscular and liver triglycerides are increased in the elderly. J Clin Endocrinol Metab. 2004;89(8):3864-71. https://doi.org/10.1210/ jc.2003-031986.

4. Petersen KF, Befroy D, Dufour S, Dziura J, Ariyan C, Rothman DL, et al. Mitochondrial dysfunction in the elderly: possible role in insulin resistance. Science. 2003;300(5622):1140-2. https://doi.org/10.1126/science.1082889.

5. Stefan N, Kantartzis K, Machann J, Schick F, Thamer C, Rittig K, et al. Identification and characterization of metabolically benign obesity in humans. Arch Intern Med. 2008;168(15):1609-16. https://doi.org/10.1001/a rchinte.168.15.1609.

6. Szendroedi J, Roden M. Ectopic lipids and organ function. Curr Opin Lipidol. 2009;20(1):50-6. https://doi.org/10.1097/MOL.0b013e328321b3a8.

7. Jacob S, Machann J, Rett K, Brechtel K, Volk A, Renn W, et al. Association of increased intramyocellular lipid content with insulin resistance in lean nondiabetic offspring of type 2 diabetic subjects. Diabetes. 1999;48(5):11139. https://doi.org/10.2337/diabetes.48.5.1113.

8. Krssak M, Petersen KF, Dresner A, Dipietro L, Vogel SM, Rothman DL, et al. Intramyocellular lipid concentrations are correlated with insulin sensitivity in humans: a 1H NMR spectroscopy study. Diabetologia. 1999;42(1):113-6. https://doi.org/10.1007/s001250051123.

9. Perseghin G, Scifo P, De Cobelli F, Pagliato E, Battezzati A, Arcelloni C, et al. Intramyocellular triglyceride content is a determinant of in vivo insulin resistance in humans: a $1 \mathrm{H}-13 \mathrm{C}$ nuclear magnetic resonance spectroscopy assessment in offspring of type 2 diabetic parents. Diabetes. 1999;48(8): 1600-6. https://doi.org/10.2337/diabetes.48.8.1600.

10. Stannard SR, Holdaway MA, Sachinwalla T, Cunningham CW. Fasting for 72 $\mathrm{h}$ increases intramyocellular lipid content in nondiabetic, physically fit men. Am J Physiol Endocrinol Metab. 2002;283(6):E1185-E91. https://doi.org/10.11 52/ajpendo.00108.2002.

11. White LJ, Robergs RA, Sibbitt WL, Jr. Ferguson MA, McCoy S, Brooks WM. Effects of intermittent cycle exercise on intramyocellular lipid use and recovery. Lipids. 2003;38(1):9-13. https://doi.org/10.1007/s11745-003-1024-x.

12. Hioki M, Kanehira N, Koike T, Saito A, Takahashi H, Shimaoka K, et al. Relationship between physical activity and intramyocellular lipid content is different between young and older adults. Eur J Appl Physiol. 2019;119(1): 113-22. https://doi.org/10.1007/s00421-018-4005-x.

13. Tsintzas K, Stephens FB, Snijders T, Wall BT, Cooper S, Mallinson J, et al. Intramyocellular lipid content and lipogenic gene exprssion responses following a single bout of resistance type exercise differ between young and older men. Exp Gerontol. 2017;93:36-45. https://doi.org/10.1016/j. exger.2017.03.018.

14. Chee C, Shannon CE, Burns A, Selby AL, Wilkinson D, Smith K, et al. Relative contribution of Intramyocellular lipid to whole-body fat oxidation is reduced with age but Subsarcolemmal lipid accumulation and insulin resistance are only associated with overweight individuals. Diabetes. 2016; 65(4):840-50. https://doi.org/10.2337/db15-1383.

15. Lexell J. Human aging, muscle mass, and fiber type composition. J Gerontol A Biol Sci Med Sci. 1995;50:11-6.

16. Hioki M, Kanehira N, Koike T, Saito A, Shimaoka K, Sakakibara H, et al. Agerelated changes in muscle volume and intramuscular fat content in quadriceps femoris and hamstrings. Exp Gerontol. 2020;132:110834. https:// doi.org/10.1016/j.exger.2020.110834. 
17. Gregory CM, Bickel CS. Recruitment patterns in human skeletal muscle during electrical stimulation. Phys Ther. 2005;85(4):358-64. https://doi.org/1 0.1093/ptj/85.4.358.

18. Vanderthommen M, Depresseux JC, Dauchat L, Degueldre C, Croisier JL, Crielaard JM. Spatial distribution of blood flow in electrically stimulated human muscle: a positron emission tomography study. Muscle Nerve. 2000; 23(4):482-9. https://doi.org/10.1002/(SICI)1097-4598(200004)23:4<482::AIDMUS5 $>3.0 . C O: 2-1$.

19. Sillen MJ, Franssen FM, Gosker HR, Wouters EF, Spruit MA. Metabolic and structural changes in lower-limb skeletal muscle following neuromuscular electrical stimulation: a systematic review. PLoS One. 2013;8(9):e69391. https://doi.org/10.1371/journal.pone.0069391.

20. Hultman E, Sjoholm H. Energy metabolism and contraction force of human skeletal muscle in situ during electrical stimulation. J Physiol. 1983;345(1): 525-32. https://doi.org/10.1113/jphysiol.1983.sp014994.

21. Hultman E, Spriet LL. Skeletal muscle metabolism, contraction force and glycogen utilization during prolonged electrical stimulation in humans. J Physiol. 1986;374(1):493-501. https://doi.org/10.1113/jphysiol.1986.sp016093.

22. Boesch C, Machann J, Vermathen P, Schick F. Role of proton MR for the study of muscle lipid metabolism. NMR Biomed. 2006;19(7):968-88. https:// doi.org/10.1002/nbm.1096

23. Provencher SW. Estimation of metabolite concentrations from localized in vivo proton NMR spectra. Magn Reson Med. 1993;30(6):672-9. https://doi. org/10.1002/mrm.1910300604.

24. Sjogaard G, Saltin B. Extra- and intracellular water spaces in muscles of man at rest and with dynamic exercise. Am J Phys. 1982;243(3):R271-80.

25. Drost DJ, Riddle WR, Clarke GD. Proton magnetic resonance spectroscopy in the brain: report of AAPM MR task group \#9. Med Phys. 2002;29(9):2177-97. https://doi.org/10.1118/1.1501822.

26. Krssak M, Mlynarik V, Meyerspeer M, Moser E, Roden M. $1 \mathrm{H}$ NMR relaxation times of skeletal muscle metabolites at 3 T. MAGMA. 2004;16(4):155-9. https://doi.org/10.1007/s10334-003-0029-1.

27. Boesch C, Décombaz J, Slotboom J, Kreis R. Obeservation of intramyocellular lipids by means of $1 \mathrm{H}$ magnetic resonance spectroscopy. Proc Nutr Soc. 1999;58(4):841-50. https://doi.org/10.1017/S002966519900114 7.

28. Weis J, Johansson L, Ortiz-Nieto F, Ahlstrom H. Assessment of lipids in skeletal muscle by LCModel and AMARES. J Magn Reson Imaging. 2009; 30(5):1124-9. https://doi.org/10.1002/jmri.21900.

29. Hioki M, Kanehira N, Koike T, Saito A, Takahashi H, Shimaoka K, et al. Associations of intramyocellular lipid in vastus lateralis and biceps femoris with blood free fatty acid and muscle strength differ between young and elderly adults. Clin Physiol Funct Imaging. 2016;36(6):457-63. https://doi. org/10.1111/cpf.12250.

30. Akima H, Hioki M, Yoshiko A, Koike T, Sakakibara H, Takahashi $\mathrm{H}$, et al. Intramuscular adipose tissue determined by T1-weighted MRI at 3T primarily reflects extramyocellular lipids. Magn Reson Imaging. 2016;34(4): 397-403. https://doi.org/10.1016/j.mri.2015.12.038.

31. Kumahara H, Schutz Y, Ayabe M, Yoshioka M, Yoshitake Y, Shindo M, et al. The use of uniaxial accelerometry for the assessment of physical-activity-related energy expenditure: a validation study against whole-body indirect calorimetry. Br J Nutr. 2004;91(2):235-43. https://doi.org/10.1079/BJN20031033.

32. Loher H, Kreis R, Boesch C, Christ E. The flexibility of ectopic lipids. Int J Mol Sci. 2016;17(9):1554.

33. White LJ, Ferguson MA, McCoy SC, Kim H. Intramyocellular lipid changes in men and women during aerobic exercise: a $1 \mathrm{H}$-magnetic resonance spectroscopy study. J Clin Endocrinol Metab. 2003;88(12):5638-43. https:// doi.org/10.1210/jc.2003-031006.

34. van Loon LJ, Koopman R, Stegen JH, Wagenmakers AJ, Keizer HA, Saris WH. Intramyocellular lipids form an important substrate source during moderate intensity exercise in endurance-trained males in a fasted state. J Physiol. 2003;553(Pt 2):611-25. https://doi.org/10.1113/jphysiol.2003.052431.

35. Koopman R, Manders RJ, Jonkers RA, Hul GB, Kuipers H, van Loon LJ. Intramyocellular lipid and glycogen content are reduced following resistance exercise in untrained healthy males. Eur J Appl Physiol. 2006; 96(5):525-34. https://doi.org/10.1007/s00421-005-0118-0.

36. Shepherd SO, Cocks M, Tipton KD, Witard OC, Ranasinghe AM, Barker TA, et al. Resistance training increases skeletal muscle oxidative capacity and net intramuscular triglyceride breakdown in type I and II fibres of sedentary males. Exp Physiol. 2014;99(6):894-908. https://doi.org/10.1113/expphysiol.2 014.078014
37. Hamada T, Sasaki H, Hayashi T, Moritani T, Nakao K. Enhancement of whole body glucose uptake during and after human skeletal muscle lowfrequency electrical stimulation. J Appl Physiol. 2003;94(6):2107-12. https:// doi.org/10.1152/japplphysiol.00486.2002.

38. Kahn BB, Alquier T, Carling D, Hardie DG. AMP-activated protein kinase: ancient energy gauge provides clues to modern understanding of metabolism. Cell Metab. 2005;1(1):15-25. https://doi.org/10.1016/j.cmet.2 004.12.003.

39. Romijn JA, Coyle EF, Sidossis LS, Gastaldelli A, Horowitz JF, Endert E, et al. Regulation of endogenous fat and carbohydrate metabolism in relation to exercise intensity and duration. Am J Phys. 1993;265(3 Pt 1):E380-91.

40. Akima H, Kubo K, Imai M, Kanehisa H, Suzuki Y, Gunji A, et al. Inactivity and muscle: effect of resistance training during bed rest on muscle size in the lower limb. Acta Physiol Scand. 2001;172(4):269-78. https://doi.org/10.1046/ j.1365-201x.2001.00869.x.

41. Vitry F, Martin A, Papaiordanidou M. Impact of stimulation frequency on neuromuscular fatigue. Eur J Appl Physiol. 2019;119(11-12):2609-16. https:// doi.org/10.1007/s00421-019-04239-x.

42. Gregory CM, Dixon W, Bickel CS. Impact of varying pulse frequency and duration on muscle torque production and fatigue. Muscle Nerve. 2007; 35(4):504-9. https://doi.org/10.1002/mus.20710.

43. Piva SR, Khoja SS, Toledo FGS, Chester-Wasko M, Fitzgerald GK, Goodpaster $\mathrm{BH}$, et al. Neuromuscular electrical stimulation compared to volitional exercise for improving muscle function in rheumatoid arthritis: a randomized pilot study. Arthritis Care Res (Hoboken). 2019;71(3):352-61. https://doi.org/10.1002/acr.23602.

44. Miyamoto T, Iwakura T, Matsuoka N, Iwamoto M, Takenaka M, Akamatsu Y, et al. Impact of prolonged neuromuscular electrical stimulation on metabolic profile and cognition-related blood parameters in type 2 diabetes: a randomized controlled cross-over trial. Diabetes Res Clin Pract. 2018;142:37-45. https://doi.org/10.1016/j.diabres.2018.05.032.

45. Boesch C, Slotboom H, Hoppeler H, Kreis R. In vivo determination of intramyocellular lipids human muscle by means of localized 1H-MRspectroscopy. Magn Reson Med. 1997;37(4):484-93. https://doi.org/10.1002/ mrm.1910370403.

\section{Publisher's Note}

Springer Nature remains neutral with regard to jurisdictional claims in published maps and institutional affiliations.

Ready to submit your research? Choose BMC and benefit from:

- fast, convenient online submission

- thorough peer review by experienced researchers in your field

- rapid publication on acceptance

- support for research data, including large and complex data types

- gold Open Access which fosters wider collaboration and increased citations

- maximum visibility for your research: over $100 \mathrm{M}$ website views per year

At $\mathrm{BMC}$, research is always in progress.

Learn more biomedcentral.com/submission 